\title{
Impactos socioculturales del turismo en el Centro Integralmente Planeado Loreto, Baja California Sur, México. Percepción de los residentes locales
}

\author{
Martha Marivel Mendoza Ontiveros* \\ José Carlos González Sosa \\ Universidad Autónoma del Estado de México
}

\section{Resumen}

Con el argumento de que una actitud favorable depende de la percepción positiva del turismo, se presenta un reporte de investigación en el que se identificaron los impactos positivos (o beneficios) y los negativos (o costos) ocasionados por el turismo, según la percepción de los residentes del Centro Integralmente Planeado (CIP) Loreto, en Baja California, México. Con una combinación de técnicas cualitativas y cuantitativas se comprobó que los habitantes del cip Loreto perciben más beneficios que costos, sobre todo en las oportunidades de empleo generadas y en la implementación de más y mejor infraestructura y servicios que, si bien son realizados para los turistas, también son disfrutados por los residentes. Por el volumen de turistas, los efectos negativos aún no son patentes para la mayoría, pero algunos prestadores de servicios turísticos perciben como "desleal" la competencia que representan los turistas de segunda residencia en el lugar.

Palabras clave

Turismo, costos, beneficios, percepción, Loreto.

Recibido: 22/10/2013 • Aceptado: 25/01/2014

*Correo electrónico: marivelmo@ hotmail.com 


\title{
Socio-Cultural Impacts of Tourism in the integrally planned Center Loreto, Baja California Sur, Mexico. Perception of local residents
}

\author{
Martha Marivel Mendoza Ontiveros* \\ José Carlos González Sosa \\ Universidad Autónoma del Estado de México
}

\begin{abstract}
With the argument that a favorable attitude depends on the positive perception of tourism, the present paper presents an research report which identified the positive impacts (or benefits) and negative impacts (or costs) incurred by tourism according to the perception of residents of Loreto, Baja California, Mexico, an Integrally Planned Center (CIP). Through a combination of qualitative and quantitative techniques, we found that the inhabitants of cIP Loreto perceive more benefits than costs, especially in the generated employment opportunities and the implementation of more and better infrastructure and services that, although made for tourists, is also enjoyed by local residents. Due to the large volume of tourists, negative effects are not yet evident for most, but some tourism service providers perceive second home tourists as "unfair" competition..
\end{abstract}

KEY WORDS

Tourism, costs, benefits, perception, Loreto. 


\section{Introducción}

La necesidad de una planificación turística y la intervención del gobierno son típicas respuestas para los efectos no deseados del desarrollo turístico (sobre todo a nivel local), a fin de hacer los destinos más atractivos o competitivos (Osorio, 2006). La planificación del sector implica concebir al turismo como un sistema complejo que forma parte de procesos ecológicos, económicos, políticos, sociales y culturales de las localidades y regiones, cuyo elevado número de variables de análisis aún no es suficientemente entendido por los modelos de planificación turística vigentes (Hall, 2005). De aquí que una adecuada distinción de las posibilidades reales de planificación para el desarrollo turístico suponga no perder de vista que se requiere construir matrices metodológicas y escenarios de impacto por actividad, es decir, elaborar estudios prospectivos multidisciplinarios donde interactúen la comunidad local y los demás actores involucrados, y donde se privilegien la coordinación y la construcción de consensos (García, 1992).

La perspectiva interdisciplinar que analiza la dimensión social del turismo presta atención, entre otros aspectos, a aquellos factores determinantes que pueden ayudar a comprender cómo son las relaciones turista-comunidad local y de qué manera la actividad turística puede estar afectada por las actitudes y percepciones de la comunidad local sobre el turismo. Sin embargo, el rápido crecimiento de este, su propia naturaleza y la ausencia de responsabilidad en él han hecho que las respuestas del sector público para sus impactos en los destinos no sean las adecuadas.

En este sentido, es imprescindible registrar los impactos del turismo en las comunidades receptoras con el fin de prevenir, mitigar o eliminar los negativos, así como incentivar o maximizar los positivos. En este artículo se presentan los hallazgos de una investigación que buscó identificar los costos y beneficios del turismo según la percepción de quienes residen en el Centro Integralmente Planeado (CIP) Loreto, Baja California, México. El documento inicia con un esbozo de lo identificado en investigaciones anteriores (como los efectos adversos o favorecedores del turismo), después se describe el contexto de estudio, el proceso metodológico empleado, los principales resultados $\mathrm{y}$, por último, se ofrecen algunos comentarios finales. 


\section{Impactos socioculturales del turismo}

Los gobiernos que desean mejorar la economía local consideran que el turismo es una importante actividad económica. No obstante, la evidencia empírica con frecuencia ha mostrado que la actividad turística es un agente transformador de la realidad territorial donde se lleva a cabo, debido a las repercusiones positivas y negativas que genera en los campos económico, social y medioambiental (Butler, 1974 y 1975; Pearce, 1988; Picornell, 1995; Murphy, 1983; Mathieson y Wall, 1982, cit. en Fernández, 2009).

Un impacto es "un cambio en un determinado tiempo como resultado de un estímulo externo” (Hall, 2005: 27). En la dimensión sociológica, el impacto social depende en gran medida del tipo de relaciones establecidas entre la comunidad local y los turistas (Butler y Pearce, 1995, cit. en Mbaiwa, 2005), es decir, las repercusiones y su magnitud dependen del tipo de encuentro. Además existen otros factores que afectan la intensidad del impacto, como el perfil del turista y la temporalidad de su estancia, entre otros. Asimismo, no es necesaria una relación intensa entre turistas y residentes para que se produzcan efectos importantes, traducidos en cambios en las actitudes, comportamientos y valores de la población autóctona (Butler, 1978, cit. en Fernández, 2009); basta con la presencia de los turistas para que se active el efecto demostración.

En este contexto, los impactos socioculturales son producto de la interacción entre la comunidad local y el turista (Smith, 1995, cit. en Fernández, 2009). Como proponen Glasson et al. (1995, cit. en Mbaiwa, 2005), los impactos sociales son los que el turismo produce en la gente, con especial atención en los cambios del día a día en la calidad de vida de los residentes de los destinos turísticos, y los impactos culturales son las modificaciones en las ideas, tradiciones y valores, normas e identidades.

De esta forma, los reportes han puesto de manifiesto predominantemente las consecuencias negativas en la comunidad local. Esta particularidad en la investigación es reconocida por Cooper et al. (2007), quienes afirman que mucha de la literatura sobre el impacto sociocultural del turismo es sesgada, pues centra la atención en lo negativo sobre la comunidad local. Así, se ha prestado poca atención al hecho de que también puede tener efectos socioculturales positivos. En realidad, los impactos socioculturales tienden a contener una mezcla de ambas vertientes que afectan tanto a los residentes como a los turistas (Cooper et al., 2007; Oppermann y Chon, 1997, cit. en Mbaiwa, 2005). 


\section{Beneficios del turismo}

Los residentes perciben de manera positiva los impactos económicos del turismo (Tatoglu et al., 2002); suelen referir los beneficios económicos en ingresos derivados de este, como los impuestos recaudados por el gobierno, que aumentan la actividad económica local; la generación de puestos de trabajo directos e indirectos, ya que disminuye la tasa de desempleo; así como las oportunidades de inversión y negocio (Davis, Allen y Cosenza, 1988; Belisle y Hoy, 1980; Ritchie, 1988; Tyrrell y Spaulding, 1984; Var, Kendall y Tarakcoglu, 1985; Tosun, 2002; Jurowski, Uysal y Williams, 1997; Lankford, 1994; Murphy, 1983; Sethna y Richmond, 1978, cit. en Royo y Ruiz, 2009).

Por otra parte, los beneficios sociales se traducen en la mejora de servicios e infraestructura pública, ya que la creciente demanda de desarrollos turísticos fomenta la inversión de nueva y mejor infraestructura en comunicación y medios de transporte (Inskeep, 1991; Milman y Pizam, 1988, cit. en Tatoglu et al., 2002), mientras que los beneficios culturales suelen observarse en un aumento de las actividades recreativas para los residentes y del orgullo y la identidad cultural, así como en oportunidades de intercambio cultural y revitalización de las tradiciones locales (Keogh, 1990; Liu, Sheldon y Var, 1987; Murphy, 1983; Pizam, 1978; Rothman, 1978; Sheldon y Var, 1984, cit. en Royo y Ruiz, 2009).

\section{Costos del turismo}

Debido a la acción de los turistas, o por los requerimientos del desarrollo de la actividad, el turismo puede afectar de manera negativa a la comunidad y tener repercusiones económicas, sociales y culturales adversas. Por ejemplo, puede elevar el precio de los bienes y servicios (Liu y Var, 1986; Pizam, 1978; Var, Kendall y Tarakcioglu, 1985, cit. en Tatoglu et al., 2002). Los ingresos del turismo, por lo general, terminan en los bolsillos de los terratenientes y hombres de negocios, en tanto que los residentes ven cómo sube el costo de la vida; lo cual es solo una mala distribución del ingreso (Do an, 1989). Por otra parte, la gente tiende a emigrar a las zonas turísticas en busca de oportunidades de trabajo, por lo que se incrementa la probabilidad de nuevos problemas sociales por la demanda de vivienda, servicios y empleo que no puede ser atendida. El turismo puede provocar un cambio gradual en los valores de una sociedad, en las creencias y las prácticas culturales (Mok, Slater y Cheung, 1991; Brunt y 
Courtney, 1999, cit. en Tatoglu et al., 2002), lo cual suele ocurrir cuando algunos residentes se identifican con los valores de los turistas y adoptan sus gustos y preferencias, que a su vez pueden tentarlos a realizar actividades delictivas para alcanzar el nivel de vida de estos. Además de sus efectos sociales, el turismo contribuye a los cambios en los sistemas de valores, el comportamiento individual, las relaciones familiares, el estilo de vida colectiva, la conducta moral y las formas de organización comunitaria (Ap y Crompton, 1998, cit. en Tatoglu et al., 2002). Es decir, puede influir de forma negativa en los valores familiares tradicionales, comercializar ritos, fiestas y tradiciones, así como crear conflictos sociales en la comunidad local (Cohen, 1988; Kousis, 1989; Tosun, 2002, cit. en Royo y Ruiz, 2009).

Algunos costos del turismo se enfocan en el plano comunitario más que en el individual. Así, la polución derivada de la basura y los residuos que generan los turistas y que se deposita en la calle y los espacios públicos es una de las afectaciones más comunes (Monterrubio et al., 2011). En 1970, Pizam (1978, cit. en Mendoza, Monterrubio y Fernández, 2011) realizó un estudio acerca de los impactos sociales del turismo en Massachusetts, donde reveló que el tránsito vehicular, el ruido, el elevado precio de bienes y servicios, el uso de drogas y el consumo de alcohol eran reconocidos como implicaciones negativas de este.

\section{Percepción}

Los impactos mencionados pueden ser evaluados positiva o negativamente mediante las percepciones de la comunidad residente. En consecuencia, se necesita entender cómo estas percepciones propician la colaboración sostenible entre los residentes, la "industria” y el gobierno.

Se conoce como percepción la función que permite al individuo recibir, elaborar e interpretar la información que llega desde su entorno, a través de los sentidos (Krech y Crutchfield, 1958, cit. en Coll et al., 1992). Así, la percepción social es el estudio de las influencias sociales sobre los individuos y su medio. Debe considerarse que las mismas cualidades pueden producir impresiones diferentes ya que interactúan entre sí de forma dinámica.

La percepción de los beneficios y costos del turismo puede estar influida por diversos factores: la dependencia del turismo, el nivel de desarrollo local, la utilización de la base de recursos públicos por parte de la población, el sentimiento hacia la comunidad y el compromiso con ella (Yutyunyong y Scott, 2009). 
Por otra parte, la respuesta o actitud de la población ante el turismo puede ser positiva o negativa en función de cómo se perciba su impacto en la comunidad receptora. En este sentido, reaccionarán de forma positiva si lo interpretan como un factor que mejora las oportunidades de ocio o incrementa la oportunidad de participar en actividades recreativas (Kendall y Var, 1984; Perdue et al., 1987; Keogh, 1990; Allen et al., 1993, cit. en Royo y Ruiz, 2009); y de forma negativa, si consideran que el turismo resulta en una masificación o expulsión de la población residente de los lugares de ocio (O’Leary, 1976, cit. en Royo y Ruiz, 2009). Lankford y Howard (1994) sugieren que las percepciones de oportunidades y participación en actividades de ocio constituyen el indicador más significativo de las actitudes hacia el turismo.

Um y Crompton (1987, cit. en Royo y Ruiz, 2009) concluyen que cuanto más vinculada se encuentra la comunidad local con la actividad turística el grado de percepción positiva de sus efectos será alto; Jurowski et al. (1997, cit. en Mbaiwa, 2005) sostienen que los residentes tienden a evaluar los impactos económicos de forma positiva y los sociales y medioambientales de forma negativa.

\section{Contexto: Centro Integralmente Planeado Loreto}

Para el Estado mexicano es evidente que el turismo es un factor destacado de la integración social y económica del país. Por lo tanto, se requirió diseñar una política turística para cada etapa de desarrollo, en la cual se identificó una marcada influencia del contexto sobre el que se pretendía actuar; sin embargo, ha habido momentos decisivos en el rumbo que ha tomado la dinámica turística nacional. Por ejemplo, desde la década de los setenta, la política del sector se caracterizó por una continuidad notable en términos de instituciones, instrumentos y estrategias, cuyos objetivos fundamentales eran aumentar los ingresos en divisas, generar empleo e integrar las regiones periféricas costeras a la economía nacional (Jiménez, 1992). No obstante, los cambios en los sistemas políticos y económicos (nacionales e internacionales), el desarrollo altamente problemático de los destinos turísticos más importantes y el mercado del turismo de sol y playa cada vez más saturado dieron lugar a una serie de modificaciones.

A mediados de los sesenta, el turismo en México se había consolidado y, en concordancia con los diversos lineamientos del Plan Nacional de Turismo 
de 1962, el gobierno mexicano emprendió una política más participativa. En correspondencia con lo establecido en este plan, que había identificado sitios favorables para la creación de nuevos complejos turísticos, se decidió concentrar los esfuerzos en cinco áreas clave: en la península de Baja California, caracterizada por una economía débil; en la costa de Jalisco y Colima, en la porción Manzanillo y Chamela; en las costas de Michoacán y Guerrero, proporcionando a Guerrero nuevas alternativas para aliviar el congestionamiento sobre el puerto de Acapulco; en las costas de Oaxaca y Chiapas, por ser de las regiones más pobres de México, y en la península de Yucatán, en especial la zona del Caribe (García, 1992).

La exploración y el análisis de las regiones propuestas se realizó durante los últimos meses de 1967 y todo 1968. De esta forma se instrumentó una estrategia de mayor alcance que consistió en construir los Centros Integralmente Planeados (CIP) -con el apoyo del Banco Interamericano de Desarrollo (BID) y bajo el mando y la coordinación del Fondo Nacional de Fomento al Turismo (Fonatur)-, que funcionarían como polos de crecimiento turístico en áreas poco desarrolladas del país (García, 1992). Los cIP se establecieron para satisfacer la demanda masiva del turismo internacional, que comenzó a acudir a lugares con determinados atributos como un buen clima (tropical o subtropical) y rasgos culturales que garantizaran diversas actividades recreativas. El objetivo principal de los cip fue convertirse en detonadores de la actividad económica local y regional. Se basaron en la llamada planeación indicativa, que se distingue por la elevada participación del Estado, tanto en la creación de la infraestructura como en las facilidades otorgadas a las corporaciones trasnacionales para captar sus capitales (García, 1992).

Los CIP son el ejemplo típico de la generación de enclaves que, según la Secretaría de Turismo (Sectur, 2000), en esencia son ordenamientos desterritorializados que no contemplan ningún compromiso en términos de capacidad de carga local; la mayoría de sus insumos y tecnología son importados, por lo que los beneficios de esta dinámica son sobre todo para los grandes inversionistas, que casi siempre son extranjeros. Sin embargo, esta política gubernamental fue diseñada e instrumentada centralmente sin consultar a los involucrados en las localidades donde se llevaron a cabo los proyectos, que al final son quienes 124 sufren los impactos y las modificaciones estructurales producidas durante la construcción, puesta en operación y consolidación de estos 


\section{Centro Integralmente Planeado Loreto}

El cIP Loreto (el corredor turístico de Loreto-Nopoló-Puerto Escondido, en Baja California Sur, México) es uno de los cinco planeados por el Fonatur en 1976, empero, su construcción inició a principios de los años ochenta.

Varios elementos marcan la historia de este poblado, entre ellos destaca el establecimiento de la primera misión de los jesuitas a finales del siglo xviI, así como los fenómenos naturales que lo afectaron: un ciclón en 1828 y un terremoto en 1878. Estas circunstancias hicieron que dejara de ser la capital del territorio peninsular.

Los primeros turistas arribaron a Loreto en la década de 1940. Por aquella época había pequeños sitios de alojamiento y comercio que se concentraban en áreas reducidas para un turismo exclusivo, principalmente de estadounidenses o mexicanos ricos (Propin, Sánchez-Crispín y López, 1998, cit. en De Sicilia, 2000). Asimismo, existían pistas privadas para avionetas y una incipiente y peligrosa comunicación marítima por medio de pequeños barcos que cruzaban el golfo de California. Desde entonces, Loreto era conocido en el mundo por su riqueza marina y sus atractivos naturales; no obstante, la mayor atracción ha girado alrededor de la pesca deportiva.

El cIP Loreto se localiza en la costa oriental del estado de Baja California Sur, frente al golfo de California. Se encuentra en el municipio de Loreto, a $337 \mathrm{~km}$ al norte de la capital del estado, La Paz, y a $1111 \mathrm{~km}$ al sur de Tijuana, ciudad fronteriza con Estados Unidos. El corredor turístico se ubica dentro de una extensa área con una superficie total de 10695 hectáreas, que incluyen espacios de asentamiento urbano, turístico, de conservación y de reserva (Fonatur, 1981). El complejo incluye a la cabecera municipal, Loreto (zona urbana, 743 hectáreas), a la bahía de Nopoló (zona turística, 3552 hectáreas) y a Puerto Escondido (zona de conservación, 6400 hectáreas), a 8 y a $28 \mathrm{~km}$, al sur de Loreto, respectivamente. Asimismo, comprende cuatro islas: Coronado, Del Carmen, Danzante y Monserrat.

El centro se ubica en el municipio de Loreto, el cual, de acuerdo con el Censo de Población y Vivienda 2010 (INEGI, 2010), cuenta con una población de 16738 habitantes, de los cuales 8892 (53.1\%) son hombres y 7856 (46.9\%) mujeres. La población no nativa representa $26.7 \%$ del total, y los estados de origen más representativos son: Sinaloa (3.9\%), Sonora (3.1\%), Oaxaca 
(2.1\%), Baja California (2\%) y el Distrito Federal (1.9\%). Los residentes del municipio nativos de otros países representan $1.4 \%$ de su población, y 88 \% de la población total del municipio se concentra en la cabecera municipal.

La población económicamente activa (PEA) es de 8 457; los sectores económicos de mayor representación son: comercio (27.5\%), servicios de alojamiento y preparación de alimentos (20.8\%), pesca y acuacultura (10.6\%) y transportes, correos y almacenamiento (10.1\%) (INEGI, 2010).

La población de Loreto tiene acceso a los servicios de agua potable (87.3\%), energía eléctrica $(89.2 \%)$ y drenaje $(90.7 \%)$. Además, cuenta con infraestructura de salud de las tres instituciones oficiales: Secretaría de Salud (3), Instituto Mexicano del Seguro Social (1) e Instituto de Seguridad y Servicios Sociales de los Trabajadores del Estado (1), las cuales se encuentran en su único centro de población urbano: Loreto.

Según cifras del INEGI (2010) referidas al grado de marginación de una zona, este municipio presenta un índice de marginación muy bajo: ocupa el sitio número 2 en el estado y, a nivel nacional, el lugar 1882 (de 2439 municipios).

Según los planes originales del Fonatur, el cIP se concluiría en 1990. Se estimó que la afluencia turística hacia Loreto-Nopoló-Puerto Escondido sería de más de 900000 turistas, de los cuales aproximadamente 750000 se dirigirían a Loreto-Nopoló y 150000 a Puerto Escondido, con un predominio de visitantes extranjeros.

Asimismo, se pensó que el grupo predominante sería el de ingresos económicos medios (Fonatur, 1981). No obstante, en 2008 el arribo de turistas fue de 158251 personas, de las cuales 73 \% eran extranjeros y $27 \%$ nacionales, en contraste con los 900000 que se esperaban en 1990. La oferta de hospedaje en 2008 fue de 508 cuartos (López Gómez, 2010), contra los 9197 previstos para 1990.

Loreto, en el contexto de los CIP, mantuvo el menor ritmo de crecimiento entre 1986-1998, sobre todo si se considera el número de cuartos, que es uno de los elementos que refleja el impacto del turismo en un lugar. Es necesario resaltar que Loreto ocupa el último sitio en número de cuartos y en arribo de turistas; sus cifras son inferiores a las de Huatulco, que es el cIP más reciente.

El despegue del CIP Loreto se ha visto frenado por factores externos, entre ellos la reducción de vuelos de la compañía aérea Mexicana en 1987, la quiebra 
de Aeronaves de México en 1988 y la desaparición de Aerocalifornia en 2008, que cubría la mayoría de la demanda para la zona de la península de Baja California. Aunado a lo anterior, se cancelaron eventos de tenis, lo que generó efectos negativos para toda Baja California Sur, pero afectaron más el aún incipiente desarrollo de Loreto. En la actualidad arriban solo unos cuantos vuelos internacionales operados por Airalaska y algunos nacionales operados por aerolíneas locales que dan servicio a la península de Baja California y zonas cercanas.

Otro elemento que repercutió en el lento despegue de Loreto fue que, en esa época, los recursos económicos programados por el Fonatur para este cIP se canalizaron preferentemente hacia otros desarrollos turísticos como Huatulco, Oaxaca, y San José del Cabo, Baja California Sur; en este último para consolidar su auge, pues ya desde mediados de siglo era visitado por turistas aficionados a la pesca.

En 2010 se proyectó el relanzamiento de Loreto como proyecto turístico con una inversión privada de alrededor de cuatro millones de dólares y pública de 800 millones de pesos, con mayor conectividad, ranchos de vino y, como atractivo adicional, la Sectur le otorgaría el título de Pueblo Mágico. Para lograr este objetivo, el director del Fonatur sostuvo pláticas con algunas aerolíneas como Volaris e Interjet para que su ruta México-Tijuana se extendiera a MéxicoLoreto-Tijuana.

En la actualidad, el anunciado "relanzamiento de Loreto" ha sido frenado por cuestiones políticas y falta de inversión, y las condiciones de su actividad turística no han mejorado desde hace algunos años (López Gómez, 2010).

\section{Descripción del proceso metodológico}

La idea de combinar metodologías cuantitativas y cualitativas es para compensar las limitaciones de ambas y fue una propuesta determinada en un estudio previo realizado en el cIP Bahías de Huatulco (Monterrubio et al., 2011), cuyo objetivo era identificar los impactos sociales del turismo a través de la percepción de la comunidad local. Con base en lo anterior, en la primera parte del trabajo de campo en el cip Loreto se utilizaron técnicas cualitativas con el fin de explorar los beneficios y costos del turismo percibidos colectiva e individualmente por la comunidad. Los resultados obtenidos en esta etapa ayudaron a 
diseñar el instrumento aplicado en el segundo trabajo de campo, sustentado en la metodología cuantitativa.

En la etapa cualitativa se empleó como instrumento la entrevista semiestructurada, se efectuaron 21 entrevistas a residentes locales durante septiembre de 2011. Al realizar la entrevista número 21 se observó una saturación de información (similitud en las respuestas de los informantes) y se consideró innecesario aplicar más entrevistas. Los informantes fueron seleccionados por conveniencia. Además de las entrevistas se tuvieron conversaciones informales, por medio de las cuales se consiguió información valiosa que apoyó la investigación.

Se elaboró un guion de entrevista para hacer las mismas preguntas a todos los informantes. Además de identificar, mediante la percepción de los residentes locales, los costos y beneficios del turismo tanto en lo individual como en lo comunitario, se prepararon otras preguntas basadas en las respuestas de los informantes con el propósito de obtener mayor información que enriqueciera el análisis.

Durante la segunda etapa de campo se empleó la encuesta como técnica de recolección de datos. Esta decisión se vio ampliamente justificada toda vez que muchas investigaciones usan instrumentos predeterminados que limitan las opciones de los informantes para indicar la diversidad de consecuencias sociales que pueden percibir (Reid, 2007, cit. en Mendoza, Monterrubio y Fernández, 2011). Lo anterior permitió establecer indicadores para el instrumento al que se recurrió en la encuesta, pero también, como se verá más adelante, para soportar mediante evidencias émic los hallazgos de esta. Los aspectos analizados en esta etapa fueron básicamente aquellos sobre los costos y beneficios del turismo percibidos por los informantes.

Una vez que se precisaron los indicadores, se diseñó el instrumento: una escala tipo Likert caracterizada por que la puntuación de cada unidad de análisis se obtiene mediante la suma de las respuestas de cada ítem. La escala se basó en el trabajo de Mendoza, Monterrubio y Fernández (2011) y se adaptó al CIP Loreto en función de una serie de ítems que reflejan una percepción positiva o negativa acerca de los referentes. Cada ítem fue estructurado con cinco opciones de respuesta.

En total, los referentes se agruparon en cuatro dimensiones:

- Impactos sociales: se incorporaron aspectos sobre la relación del turismo con el incremento o la disminución de la delincuencia, la prostitución, 
el consumo de drogas, el hacinamiento, las oportunidades de recreación, entre otros.

- Impactos culturales: se integraron temas referentes al turismo y las oportunidades de intercambio cultural, los cambios en las costumbres y tradiciones a causa de la actividad turística y cómo el turismo puede influir en los valores y el estilo de vida en la comunidad, etcétera.

- Impactos económicos: se incluyeron tópicos como la inversión del gobierno gracias al turismo, la actividad turística como detonante de nuevas actividades económicas en la comunidad, el turismo como proveedor de empleos, si estos trabajos son considerados bien remunerados, si el turismo demanda mano de obra especializada, por citar algunos.

- Impactos de turistas americanos con casa en la comunidad: esta dimensión fue incluida debido a que en los hallazgos del trabajo de campo cualitativo el turismo residencial fue un tema reiterado por los entrevistados, a diferencia de los resultados del trabajo de investigación en Huatulco; los temas en esta dimensión se relacionan con los empleos generados por este tipo de turistas, los beneficios que producen hacia la comunidad, su competencia con los prestadores de servicios locales, entre otros.

Además de las cuatro dimensiones citadas, hubo una sección sobre aspectos sociodemográficos que buscó establecer características de los participantes de la muestra (género, lugar de nacimiento, tiempo de residencia y edad), que se han revelado como factores que influyen en la percepción de los impactos sociales del turismo (Harrill, 2004, cit. en Mendoza, Monterrubio y Fernández, 2011).

El instrumento cuantitativo fue sometido a una prueba piloto durante noviembre de 2011 en los principales espacios urbanos de Loreto. A partir de los datos del estudio piloto, se definió el tamaño de la muestra con base en el número de habitantes en Loreto (16 738) y la fórmula estadística para poblaciones finitas. En total se aplicaron 68 cuestionarios atendiendo a un nivel de confianza de $90 \%$ y un error muestral de $10 \%$.

El estudio completo se realizó en noviembre de 2011 e incluyó fundamentalmente a residentes mayores de 18 años que fueron seleccionados por conveniencia. Por último, la concentración y el análisis de los datos se realizaron mediante el uso del software spss (Statistical Package for Social Sciences). 


\section{Los costos y beneficios del turismo percibidos por los habitantes del cIP Loreto}

\section{Perfil sociodemográfico}

En la primera etapa del trabajo de campo se realizaron entrevistas a 21 personas: nueve mujeres y 12 hombres, con edades que fluctuaban entre los $21 \mathrm{y}$ los 70 años. El promedio de tiempo de residencia de los participantes fue de 31 años. Diez entrevistados son originarios de Loreto, dos más provienen de otro lugar de Baja California Sur (San José de Comondú y La Paz), siete de otro estado de la república (Guerrero, Puebla, Sonora, Veracruz y Michoacán) y solo dos son de otro país (Estados Unidos e Italia). La mayoría de los entrevistados poseía un grado de escolaridad por encima de la educación básica.

En el trabajo de campo cuantitativo participaron 68 personas, 31 mujeres y 37 hombres, cuyas edades oscilaron entre los 18 y los 74 años. En este grupo había personas con cuatro años de residencia en Loreto y otras que han vivido ahí toda su vida.

\section{Beneficios percibidos}

\section{SOCIALES}

Uno de los beneficios sociales más defendidos del turismo es la mejora de los servicios y la infraestructura pública en los destinos turísticos, tal como han señalado Sethna y Richmond (1978, cit. en Royo y Ruiz, 2009) y Pizam (1978, cit. en Tatoglu et al., 2002).

En el cIP Loreto la gente percibe que el turismo ha favorecido a la comunidad con la mejora de infraestructura; más construcciones, mayor número de hospitales, clínicas y escuelas. Quienes dijeron estar totalmente de acuerdo o de acuerdo (percepción positiva) con la afirmación de que el turismo ha traído más construcciones sumaron $60.2 \% ; 32.3 \%$ contestó no estar ni de acuerdo ni en desacuerdo (opinión neutral), y quienes están en desacuerdo y totalmente en desacuerdo (percepción negativa) suman 7.3\%; 85.2\% de los participantes consideran que el turismo ha mejorado la infraestructura (percepción positiva), 7.3 \% permanece neutral y $7.2 \%$ tiene una percepción negativa (gráfica 1). 


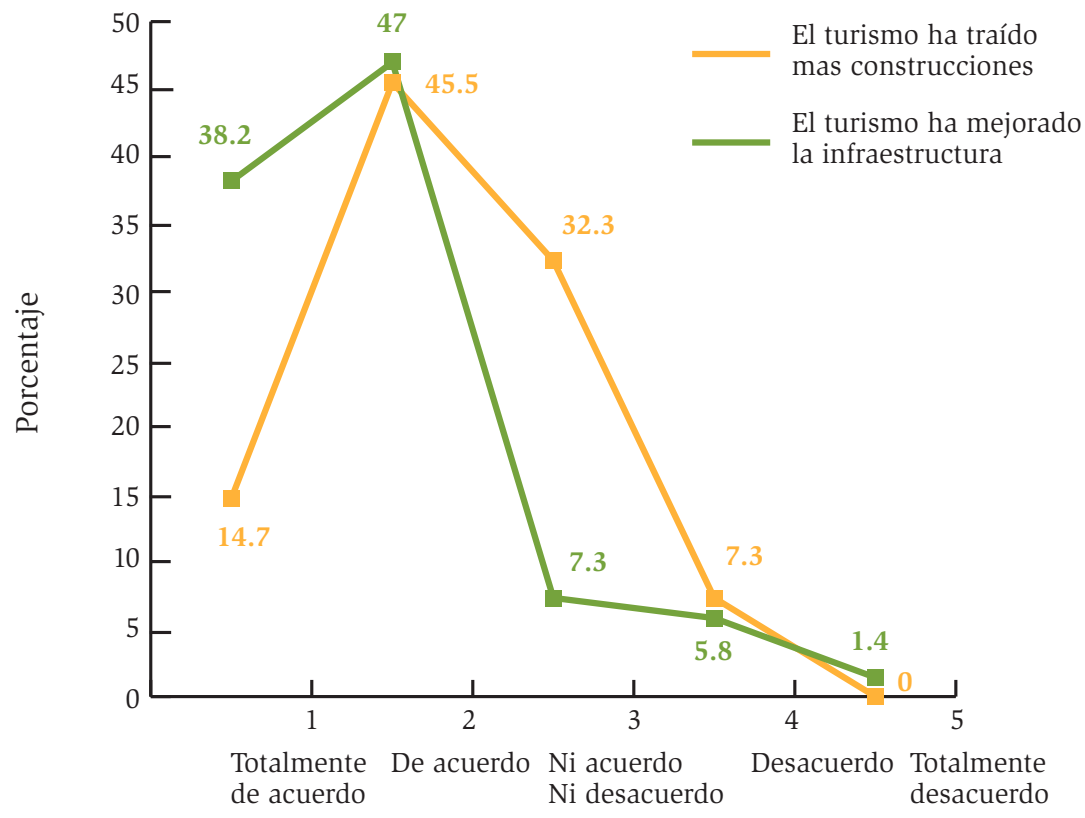

Fuente: Elaboración propia.

\section{Gráfica 1. Infraestructura}

Estas cifras, en particular las vinculadas con la mejora en la infraestructura, también fueron ampliamente reconocidas durante las entrevistas. Sobre el tema, fue común escuchar afirmaciones como las siguientes:

Yo noto el beneficio en las calles pavimentadas, en el malecón y el alumbrado público, recuerdo cuando Loreto era más tradicional, más pequeño [Sonia, comerciante].

Recuerdo, por ejemplo, que gracias a que abrieron los primeros hoteles en Loreto, llegó el primer teléfono acá, antes no había teléfono [Manuel, pescador].

Además, 77.8 \% sostiene que el turismo ha incrementado el número de escuelas, $16.1 \%$ mostró una postura neutral y $5.8 \%$ negativa. Ante la afirmación de que el turismo ha aumentado la cantidad de hospitales y clínicas en la comunidad, $83.7 \%$ tiene una percepción positiva, $7.3 \%$ neutral y $8.8 \%$ negativa. La gráfica 2 evidencia que prevalecen las percepciones positivas. 


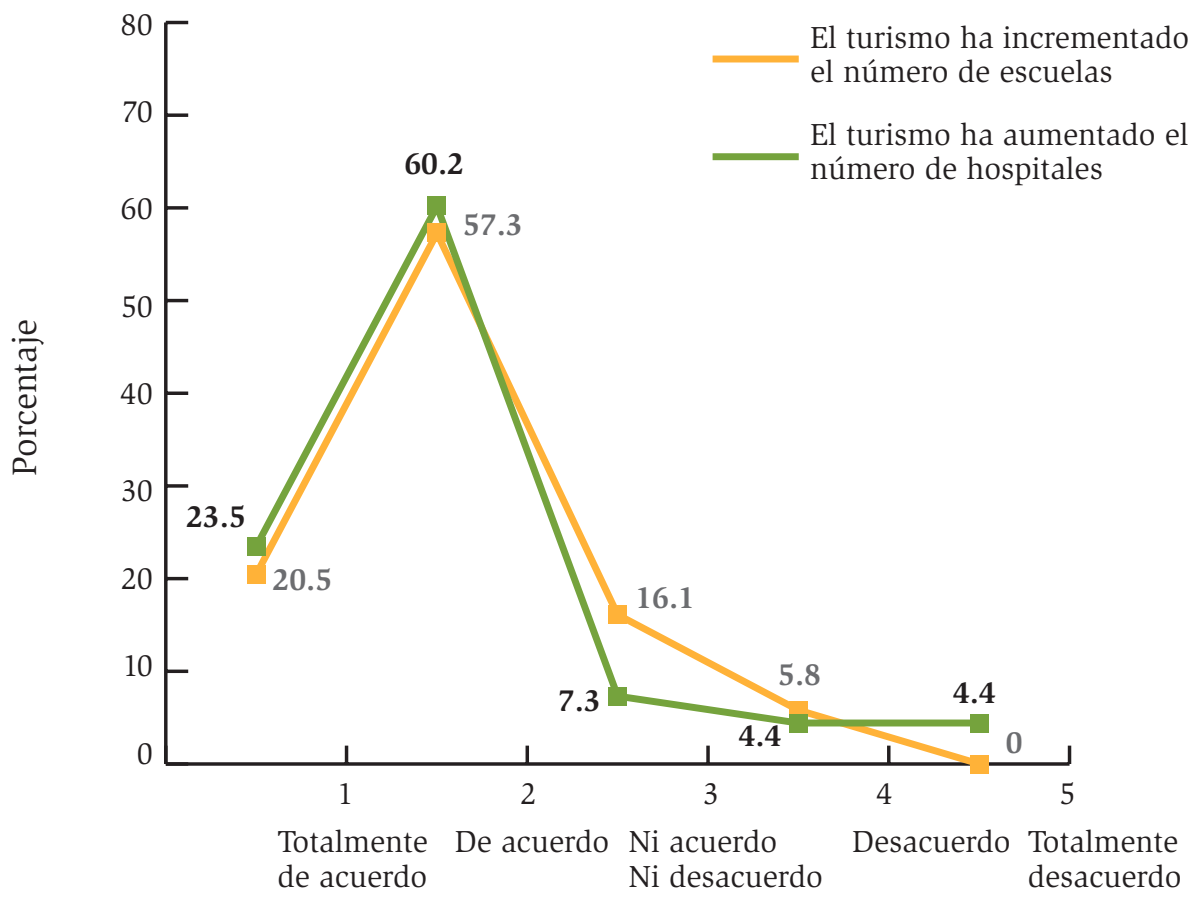

Fuente: Elaboración propia.

Gráfica 2. Servicios Públicos

Respecto a estas cifras, correspondientes al incremento en el número de escuelas, en la etapa cualitativa se encontró que:

Ya hasta una universidad hay, cuándo me iba a imaginar que iban a poner una universidad aquí... yo creo por el mismo turismo la pusieron, la principal carrera es la Licenciatura en Turismo Alternativo... está bien para que ayude a mejorar el turismo [Mónica, comerciante].

Por otra parte, los beneficios sociales también se traducen en más actividades lúdicas para los residentes: $69 \%$ de los encuestados piensa que el turismo incrementa las oportunidades de recreación, $16.1 \%$ tiene una percepción neutral y $14.6 \%$ negativa. A su vez, $77.9 \%$ percibe positivamente la afirmación de que el turismo favorece la promoción de la comunidad como destino turístico, $5.8 \%$ se mostró neutral y $16.1 \%$ la juzga negativamente. 


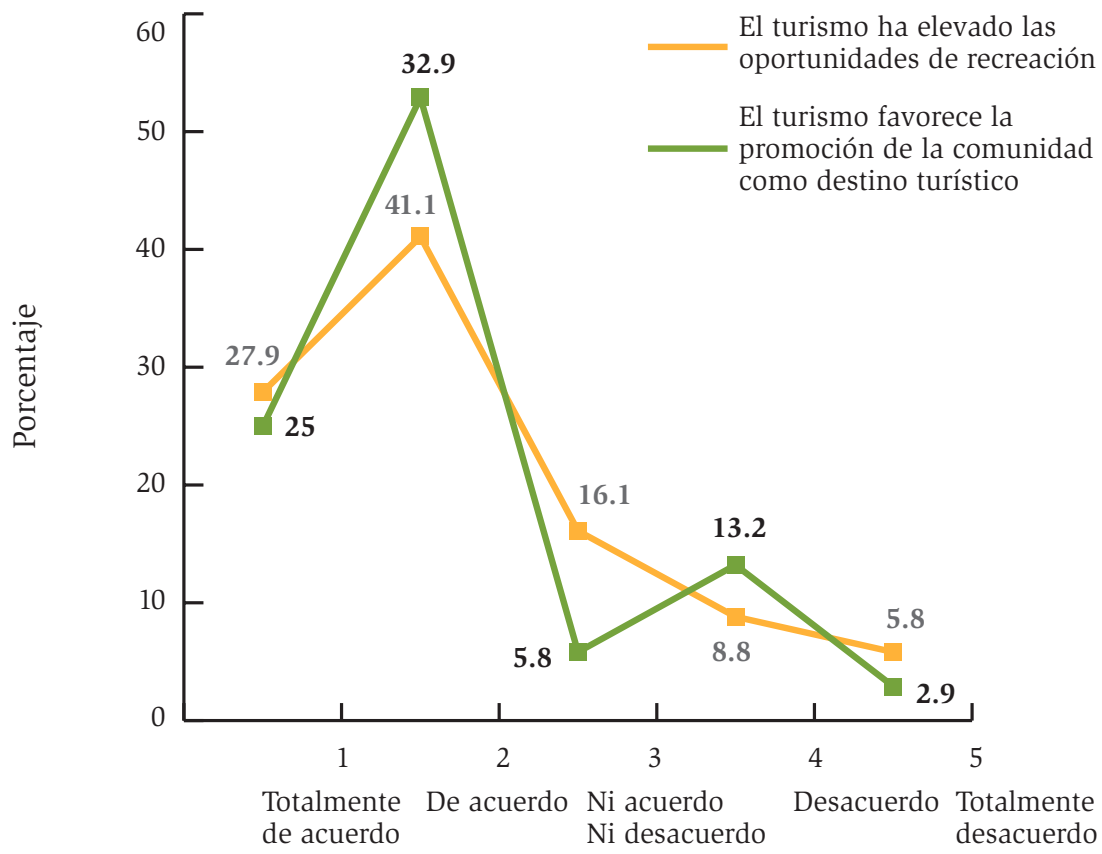

Fuente: Elaboración propia.

Gráfica 3. Recreación y promoción

\section{CULTURALES}

En investigaciones previas se ha hallado que el turismo incrementa el orgullo y la identidad cultural, la cohesión y la reciprocidad de ideas, así como la calidad de vida, y mejora el conocimiento de la cultura de la zona y la imagen de la comunidad. Sobre estos asuntos, en la encuesta se encontró que 69 \% coincide en que el turismo hace que la comunidad se sienta orgullosa de vivir en Loreto, $23.5 \%$ permanece neutral y $7.3 \%$ lo percibe negativamente. Ante la afirmación de que el turismo provoca que la comunidad esté unida, la respuesta fue positiva por $53.8 \%, 26.4 \%$ neutral y $19 \%$ negativa; $49.9 \%$ estima que el turismo mejora la imagen de la comunidad, $23.5 \%$ se muestra neutral y $26.4 \%$ difiere de esto. 


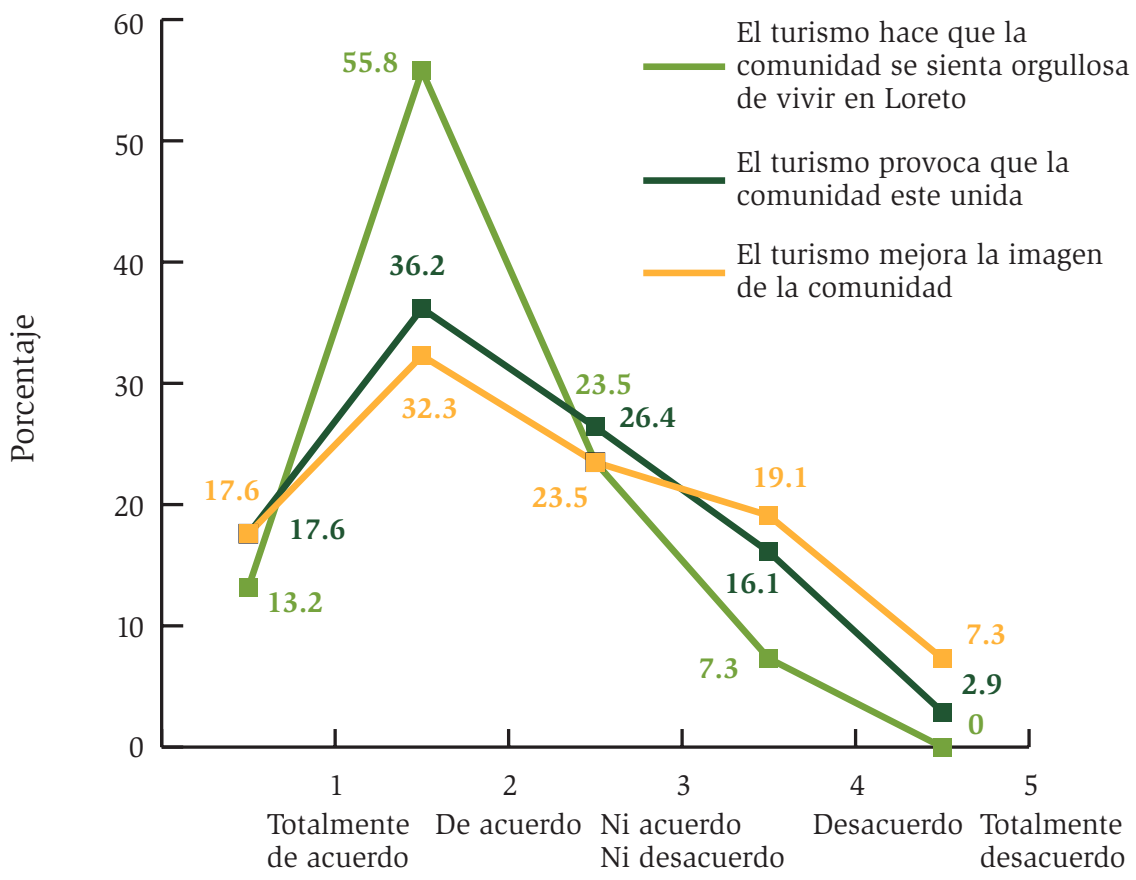

Fuente: Elaboración propia.

Gráfica 4. Orgullo, unidad e imagen en la comunidad

Así, los entrevistados dijeron:

Ahora Loreto es más grande, ha cambiado su imagen, se ve más moderno y desarrollado... esa buena imagen atrae más turismo [Sonia, comerciante].

En conversaciones informales afloró lo siguiente:

Uno como loretano [gentilicio para los habitantes de Loreto] se siente orgulloso de su comunidad, de recibir al turismo y atenderlos muy bien... yo me siento feliz de vivir en Loreto [Alfredo, mesero].

También se ha sostenido que el turismo crea oportunidades de intercambio cultural y revitaliza las tradiciones locales (Besculides, Lee y McCormick, 2002, cit. en Royo y Ruiz, 2009). En lo relativo a las oportunidades de intercambio 
cultural, $63.2 \%$ opina que sí las hay, $10.2 \%$ se muestra neutral ante esta afirmación y $26.4 \%$ dice que no las hay. En la gráfica 5 se observa una percepción positiva similar ante la aseveración de que el turismo revitaliza las tradiciones locales, con $57.3 \%$ de opinión positiva, $17.6 \%$ neutral y $24.9 \%$ negativa.

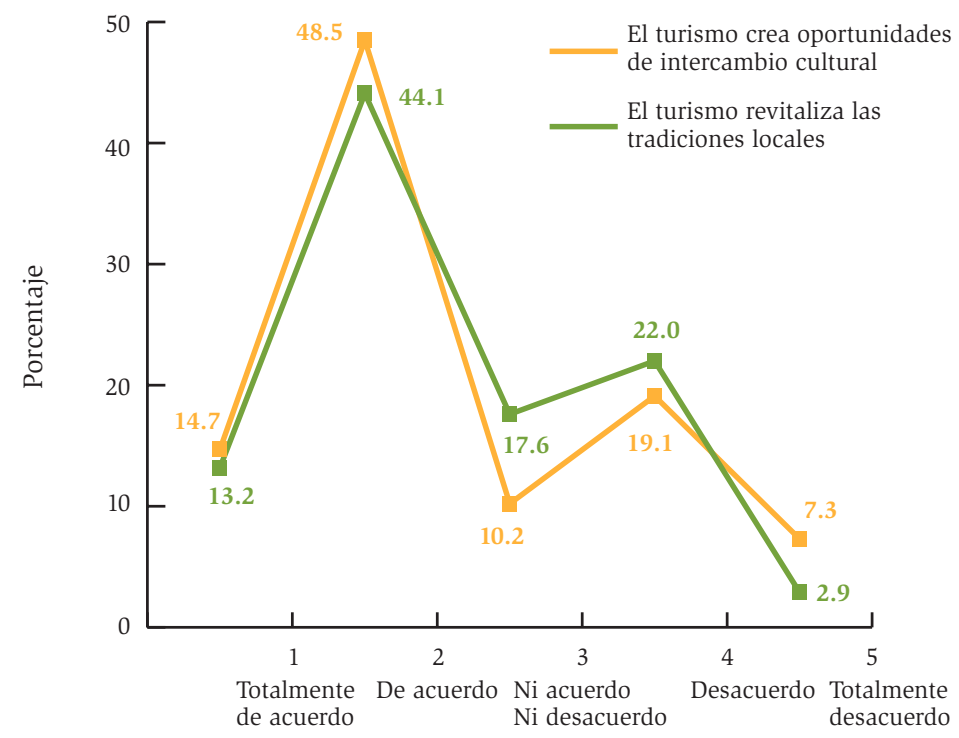

Fuente: Elaboración propia.

Gráfica 5. Intercambio cultural y tradiciones

En algunas pláticas informales se obtuvieron comentarios como:

Aún hay tradiciones aquí, nuestras fiestas son reconocidas en el estado [Baja California Sur]... en septiembre la fiesta de nuestra señora de Loreto, nuestra patrona... en octubre celebramos la fundación de Loreto... el turismo llega en esta época y las fiestas nos identifican como loretanos [Rodrigo, comerciante]. 


\section{ECONÓMICOS}

Los impactos económicos del turismo por lo general son percibidos de forma positiva por los residentes (Gee, Makens y Choy, 1997; Liu y Var, 1986; Dogan, 1987, cit. en Tatoglu et al., 2002). El turismo puede generar empleos indirectos en las industrias de servicios relacionadas mediante la demanda de productos locales suministrados a los establecimientos, que no existirían sin los turistas (Haley y Haley, 1997, cit. en Royo y Ruiz, 2009).

En el caso del CIP Loreto, de acuerdo con la información de las entrevistas, el turismo ha mostrado un impacto positivo que se refleja en el beneficio económico a través de los empleos directos e indirectos que trae consigo. Esta información se respalda en la literatura, donde se señala que el turismo puede crear puestos de trabajo directos mediante la contratación de las personas de la localidad en hoteles, restaurantes y servicios de entretenimiento turísticos que atienden a los turistas.

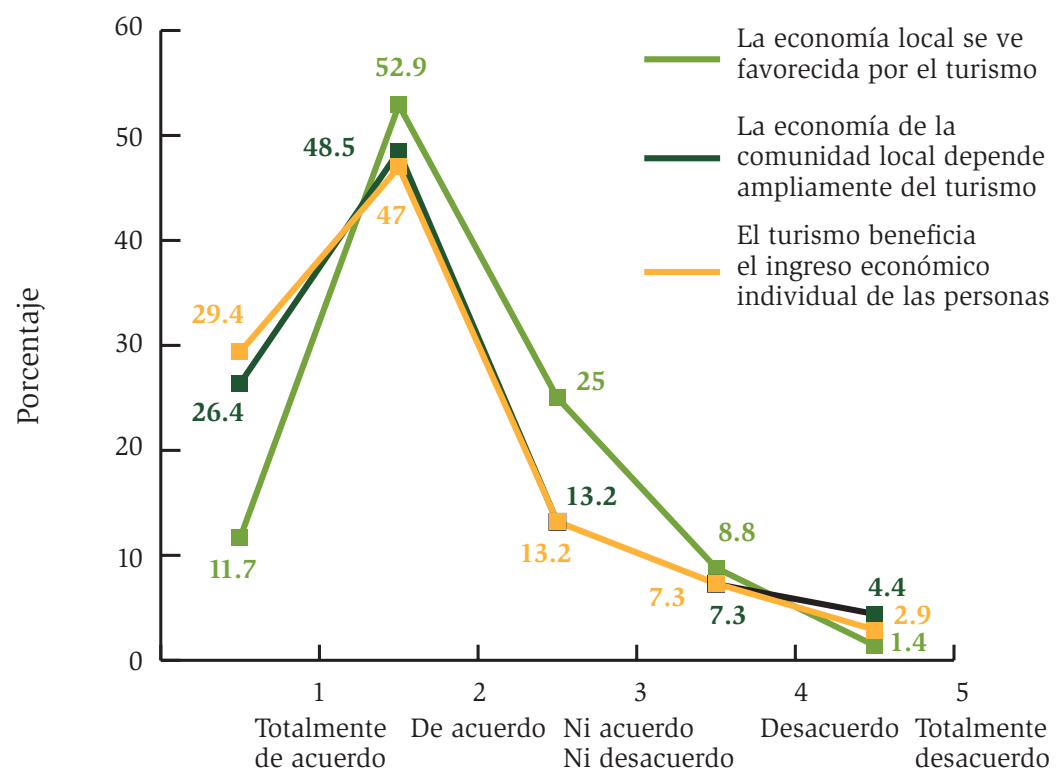

Fuente: Elaboración propia.

Gráfica 6. Economía local 
En este sentido, acerca de los beneficios económicos del turismo predomina la percepción positiva en el cIP Loreto (gráfica 6): 64.6 \% cree que la economía local se ve favorecida por el turismo; $25 \%$ es neutral y $10.2 \%$ lo percibe de manera negativa. Al interrogante de si la economía de la comunidad local depende ampliamente del turismo, $74.9 \%$ tiene una percepción positiva, $13.2 \%$ neutral y $11.7 \%$ negativa. Asimismo, en lo que se refiere al turismo y al mayor ingreso económico local, 76.4 \% asume que así es, $13.2 \%$ tiene una postura neutral y $10.2 \%$ considera que no es así.

$\mathrm{Al}$ respecto los entrevistados comentaron:

¡OK!, ahorita está bajo [el turismo], pero yo creo que la gran mayoría vivimos del turismo, si no hubiera turismo, Loreto no existiría [Mayra, recamarera].

A causa del turismo surgen nuevas actividades económicas en la comunidad, lo cual fue apoyado por $63.2 \%$ de los participantes, $13.2 \%$ permaneció neutral y $23.4 \%$ contestó negativamente. Del mismo modo, $73.4 \%$ sostuvo que el turismo beneficia a los diferentes sectores de la comunidad, $16.1 \%$ tiene una posición neutral y $10.2 \%$ negativa.

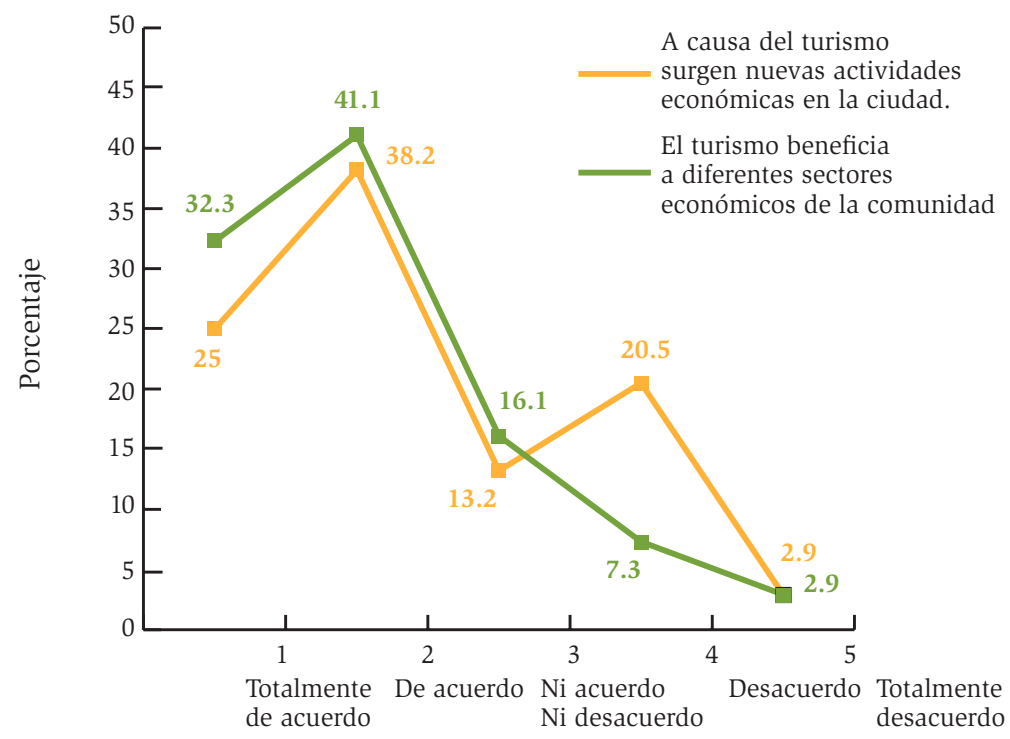

Gráfica 7. Actividades económicas 
Al no tener actividades económicas importantes como industria, ganadería, agricultura, pesca comercial, etc., Loreto basa gran parte de su economía en el turismo:

Mi trabajo se lo debo al turismo porque aquí no hay nada, puro desierto, no hay ganado, no hay cosecha, no hay fábricas... yo no sé qué sería de Loreto si no existiera el turismo [Mónica, comerciante].

La economía en Loreto se divide en dos: el turismo sería el 90 \% y el ayuntamiento el $10 \%$ de la economía, no hay más trabajo, de hecho toda mi familia vive del turismo, mi papá trabaja en el aeropuerto y mi pareja trabaja en otro hotel [Martha, recepcionista].

En la gráfica 8 se muestra que la idea positiva sobre los indicadores económicos es mayoritaria. Sobre la percepción de que el turismo demanda mano de obra especializada para sus diversos fines, $63.1 \%$ considera que es así, $14.7 \%$ se mantiene neutral, y $22 \%$ piensa que el turismo en Loreto no demanda mano de obra especializada; $64.6 \%$ opina que el turismo aumenta las oportunidades de comercio en la comunidad, en una postura neutral se ubica $19.1 \%$ y $16 \%$ estima que no hay tal aumento.

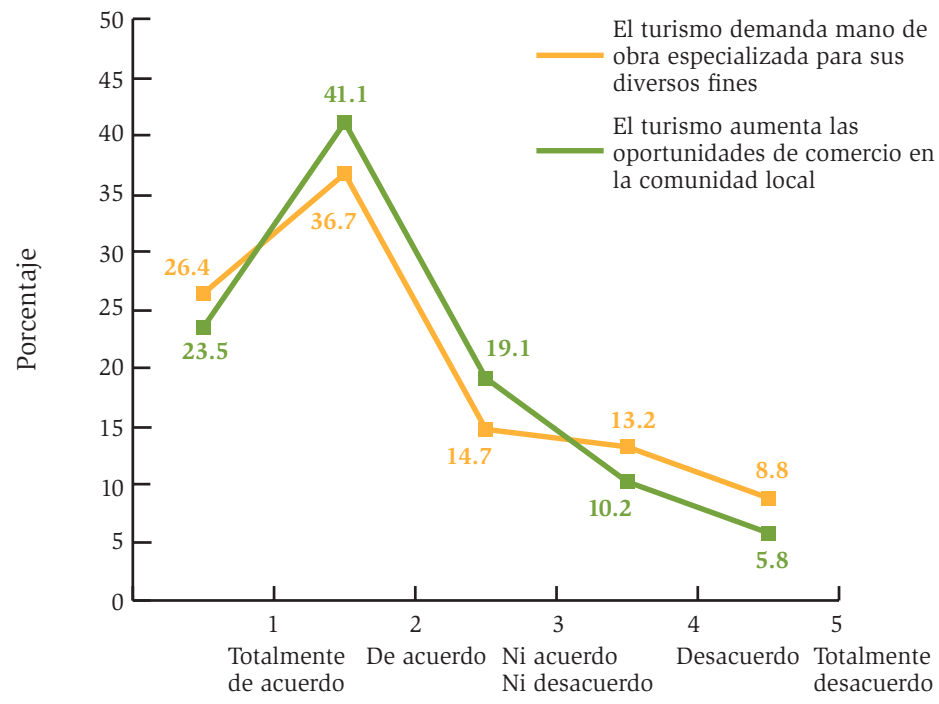

Fuente: Elaboración propia.

Gráfica 8. Mano de obra y oportunidades de comercio 
Al respecto, un entrevistado mencionó:

Por eso me regresé acá [Loreto], para abrir mi negocio... aquí vi la posibilidad de poner mi restaurante y espero funcione... yo creo que así será, el turismo lo levanta mucho [Miguel, propietario de restaurante].

Por otra parte, la creciente demanda de un desarrollo turístico fomenta la inversión de nueva infraestructura (Inskeep, 1991, cit. en Tatoglu et al., 2002): $75 \%$ de la muestra afirmó que el turismo genera inversión del gobierno en la comunidad, $13.2 \%$ no está ni de acuerdo ni en desacuerdo, y $11.7 \%$ piensa que no es así. En tanto, 74.8 \% está totalmente de acuerdo o de acuerdo en que el turismo atrae inversión del sector privado internacional hacia la comunidad, $16.1 \%$ se mantiene neutral y $8.7 \%$ rechaza este postulado.

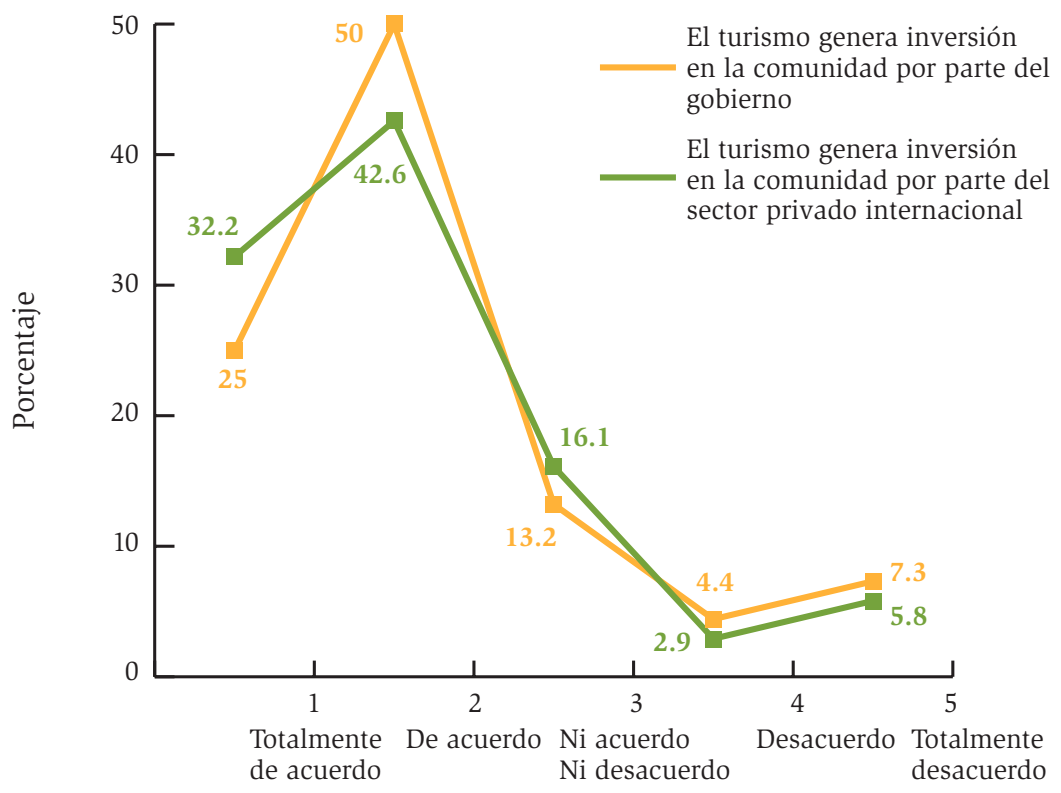

Fuente: Elaboración propia. 
Con una apreciación positiva (44\%) se sostiene que el turismo genera inversión del sector privado nacional en la comunidad, en una percepción neutral se encuentra $11.7 \%$ y en una perspectiva negativa se halla $44 \%$. Respecto a si el turismo genera inversión por parte del sector privado local, $35.2 \%$ tiene una percepción positiva, $10.2 \%$ neutral y $54.4 \%$ argumenta que no lo ve como un efecto del turismo.

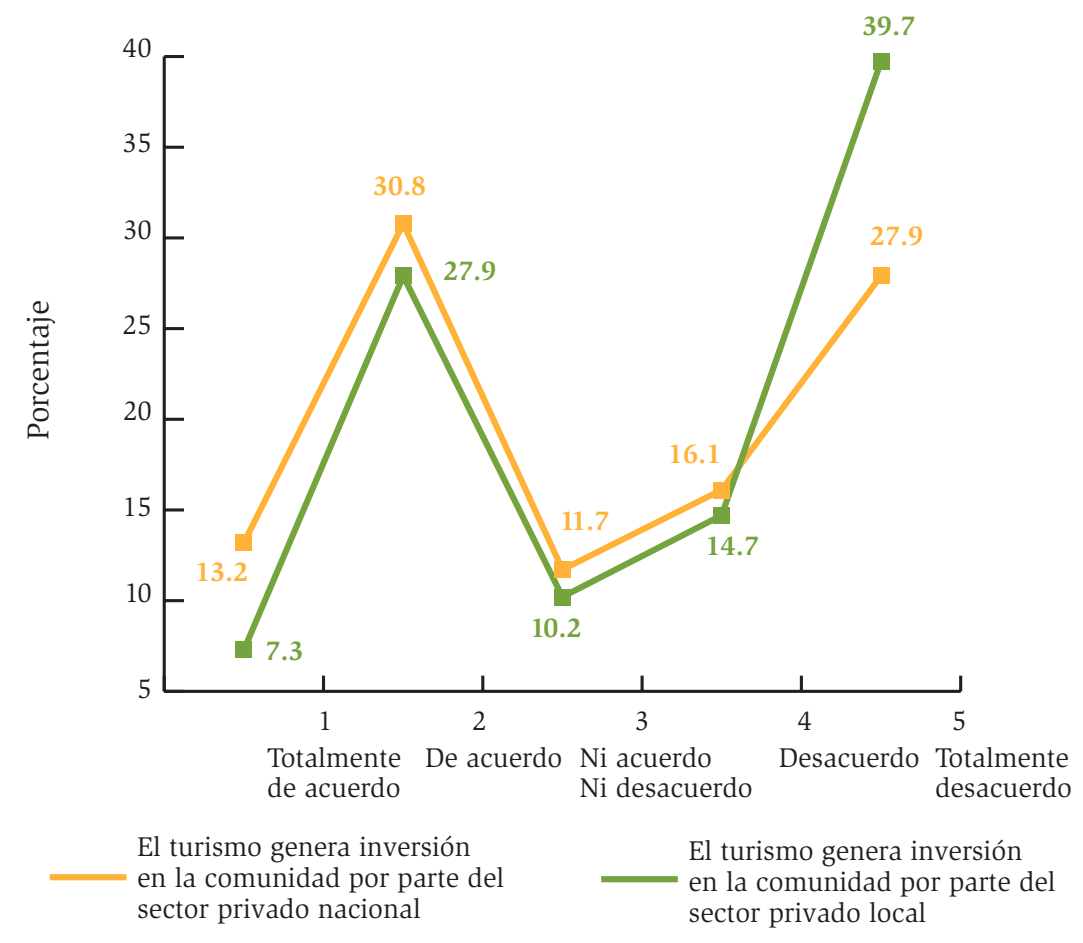

Fuente: Elaboración propia.

Gráfica 10. Inversión del sector privado nacional y local

Turistas americanos con casa en la comunidad (turismo de segunda residencia)

En conversaciones informales se detectó, por un lado, que el turismo de segunda residencia ha traído ciertos beneficios a la comunidad y, por otro, que 
empiezan a surgir algunos costos. De acuerdo con algunos entrevistados, el turismo residencial comienza a convertirse en un problema principalmente para los pescadores y los taxistas, ya que varios grupos de americanos realizan un tipo de competencia "desleal”, según palabras de los entrevistados, con los trabajadores locales, lo cual impacta a su vez de forma negativa en la economía de algunos residentes y provoca desempleo.

Cuando se les preguntó si el turista americano con casa en la comunidad reduce las oportunidades de empleo directo de la comunidad, $64.6 \%$ afirmó que sí, $13.2 \%$ se mantuvo neutral y $22 \%$ contestó que no. En Loreto, 64.6\% considera que el turista americano con casa en la comunidad provoca escasez de servicios, 5.8 \% no está ni de acuerdo ni en desacuerdo, y $29.3 \%$ cree que no hay relación entre estos turistas y la escasez de servicios en la comunidad.

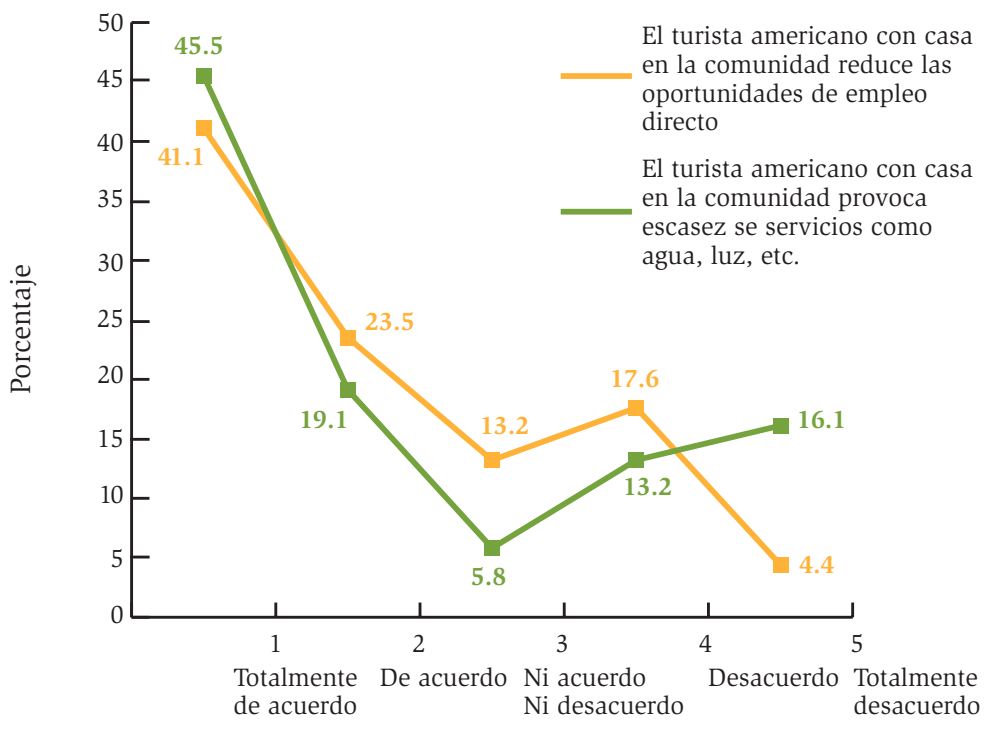

Fuente: Elaboración propia.

Gráfica 11. Oportunidades de empleo y escasez de servicios 


\section{Algunos entrevistados mencionaron:}

Este tipo de turismo nos afecta a todos los transportistas... ya le incluye todo para ir a pescar, la casa y toda la transportación... eso es lo que nos afecta... los americanos que se quedaron acá... uno dice: no está mal que se queden, son libres de hacerlo, pero ya que vengan y hagan sus negocios acá, eso ya está mal... están viendo que casi no hay turismo y el poco que pudiera llegar se lo jinetean... cómo voy a creer... échese una vuelta al aeropuerto, se va a cerciorar que mucha gente de aquí americana, dizque van por sus "amigos”... ¡No, que es mi amigo... Vengo por él! [lo expresa imitando a un turista estadounidense], pero ya le está dando el servicio de hotel, el servicio de barco, ya le está dando el servicio de transportación, eso es lo que nos afecta a nosotros los taxistas [Michael, taxista].

Los servicios de luz y agua escasean en temporada alta. Al respecto, un entrevistado comentó:

Cuando es la temporada alta, que es de octubre a mayo, sí disminuye el abasto de agua... yo creo que porque somos más con la llegada de los turistas y no alcanza para todos... pero pues yo no creo que se la quiten a los hoteles o a los condominios de los gringos [turista estadounidense] la verdad... y con la luz lo mismo [Aldo, comerciante].

En cuanto a los costos de los turistas estadounidenses con casa en la comunidad, los encuestados distinguen que representan competencia desleal para los prestadores de servicios turísticos locales $66 \%$ está totalmente de acuerdo o de acuerdo, $8.8 \%$ ni de acuerdo ni en desacuerdo y $24.9 \%$ en desacuerdo o totalmente en desacuerdo).

\section{Percepción del turismo}

Para dar más profundidad a la investigación, la percepción de los residentes sobre la actividad turística también fue explorada en el trabajo de campo cualitativo. La mayoría de los entrevistados se muestra favorable a la actividad turística, muchos señalaron esperar mejores momentos y oportunidades con el turismo en Loreto.

Qué bueno que el turismo mantenga a Loreto... no sé qué sería sin él... el futuro de Loreto se encuentra en el turismo... vienen tiempos muy buenos para Loreto, ya 
hay más publicidad... la gente empieza a venir más y si llegaran a venir mucho más, eso va a ser muy bueno para todos [José, gerente de hotel].

Está bien que vengan los turistas, nos dan trabajo, si vinieran más estaría mucho mejor la situación... ahorita está muy bajo el turismo pero ya mejorará... es lo mejor para Loreto [Mario, taxista].

Yo sí me beneficio del turismo, está muy bien que vengan a gastar y ayudar a la economía de la comunidad... está muy, muy bien [Aldo, comerciante].

Yo sí quisiera que fueran más los turistas que nos visitan, pero el poco turismo que viene es bien recibido [Raquel, cocinera].

\section{Consideraciones finales}

Los resultados revelan que los residentes locales apoyan el turismo ya que se aprecian más beneficiados que afectados (en cuanto a empleos, infraestructura, inversión, entre otros aspectos), por ello se advierte una actitud favorable o positiva hacia el turismo y están deseosos de que Loreto siga creciendo para recibir más turismo. Sin embargo, algunos residentes creen que los costos del turismo prevalecen sobre los beneficios (problemas sociales y ambientales, cambio en el estilo de vida, empleos mal pagados, entre otros). De esta forma, desde la teoría del intercambio social se evidencia que estas personas tendieron a evaluar los impactos de forma negativa. Los residentes están dispuestos a participar en tal intercambio si creen que es probable obtener beneficios sin incurrir en costos inaceptables (drogadicción, prostitución, alcoholismo, competencia desleal por parte de turistas residenciales, entre otros). Así, quienes perciben que los beneficios son mayores que los costos están dispuestos a participar en el intercambio y, por lo tanto, apoyan el desarrollo del turismo local futuro porque de ello viven u obtienen su sustento.

Asimismo, no se perciben efectos como la generación de basura, el incremento en el tráfico vehicular, aglomeraciones en espacios públicos o aquellos impactos que han emergido en destinos con una mayor afluencia de turistas.

En general, la comunidad local del cIP Loreto observa que el turismo les trae más beneficios, sobre todo en lo económico y en las obras y programas 
sociales y ambientales que realizan los turistas americanos con casa en la comunidad (que pretenden mejorar el lugar donde viven algunos meses del año) o las personas jubiladas que buscan un buen sitio para pasar sus últimos años. Estos turistas hacen campañas de limpieza en las playas, así como donativos a escuelas y centros de salud e impulsaron el uso del cinturón de seguridad en los automóviles para evitar muertes en accidentes.

Cabe mencionar que la percepción es un acto subjetivo que puede no corresponder con la realidad objetiva, pues se percibe desde los marcos de referencia, la historia personal y la experiencia de vida; no obstante, esto no puede ser descalificado o ignorado, ya que a partir de la percepción se toman posturas o se responde a una situación determinada. De ahí la relevancia de conocer el punto de vista de la comunidad; identificar los beneficios y los costos que le atribuyen al turismo puede dar una idea de qué está viendo la gente para predecir el rumbo de sus decisiones y comportamiento.

Como hipótesis puede postularse que estos resultados se deben en gran medida a que el turismo en el crp Loreto no se ha masificado como por ejemplo en Cancún y por el perfil del turista que los visita, pues van más para estar en contacto con la naturaleza haciendo actividades como la pesca deportiva o la observación de aves, ballenas o delfines, por lo que aún sienten más beneficios que problemas.

Por otra parte, se puede inferir que la percepción de la comunidad local sobre los costos y beneficios del turismo (impactos) no es homogénea, existen variados puntos de vista. Durante los trabajos de campo se comprobó que los residentes que tienen un beneficio directo (económico), como los meseros, restauranteros, recepcionistas, hoteleros, entre otros, tendieron a evaluar positivamente los impactos del turismo: aquellos que se encontraban lejos de las áreas con actividad turística se mostraron neutrales en su percepción; y aquellos afectados por los costos del turismo (económico y social), como taxistas y pescadores, principalmente, hacían evidente su desaprobación hacia el turismo y sus impactos.

\section{Fuentes consultadas}

144 Coll, C. et al. (1992). Enseñanza y aprendizaje de conceptos, procedimientos y 
actitudes. México: Santillana.

Cooper, Ch. et al. (2007). Turismo, teoría y práctica. Madrid: Síntesis.

Do an, H. (1989). "Forms of Adjustment - Sociocultural Impacts of Tourism". Annals of Tourism Research, 16 (2), 216-236.

Fernández, J. (2009). "Los debates sobre la percepción del turismo en las Islas Baleares”. Nimbus, 23-24, 5-24.

Fonatur (1981). Un nuevo desarrollo turístico en Baja California Sur. México: Fondo Nacional de Fomento al Turismo.

García, A. (1992). La planificación de centros turísticos de México. México: Limusa.

Hall, C. (2005). Tourism Planning: Policies, Processes and Relationships. Londres: Routledge.

INEGI (2010). Anuario Estadístico del Estado de Baja California Sur. México: Instituto Nacional de Estadística y Geografía.

Jiménez, A. (1992). Turismo: estructura y desarrollo. México: McGraw-Hill.

Lankford, S. y R. Howard (1994). "Developing a Tourism Attitude Impact Scale”. Annals of Tourism Research, 21 (1), 121-139.

López Gómez, J.A. (2010). "Sectur alista relanzamiento de Loreto, BC”. El Universal [en línea], 7 de junio. Disponible en: http://www.eluniversal. com.mx/notas/686037.html [2011, 27 de noviembre].

Mbaiwa, J. (2005). "The Socio-cultural Impacts of Tourism Development in the Okavango Delta, Botswana”. Journal of Tourism and Cultural Change, 2 (3), 163-185.

Mendoza, M.M., J.C. Monterrubio y M.J. Fernández (2011). “Impactos sociales del turismo en el Centro Integralmente Planeado (CIP) Bahías de Huatulco, México". Gestión Turística, 15, enero-junio, 47-73.

Monterrubio, J.C. et al. (2011). "Turismo y cambios sociales. Estudio cualitativo sobre percepciones comunitarias en Bahías de Huatulco, México”. Cuadernos de Turismo, 28, julio-diciembre, 171-189.

Osorio, M. (2006). "La planificación turística. Enfoques y modelos”. Quivera, 8 (1), 291-314.

Royo, M. y M.E. Ruiz (2009). "Actitud del residente hacia el turismo y el visitante: factores determinantes en el turismo y excursionismo ruralcultural”. Cuadernos de Turismo, 23, enero-junio, 217-236. 
Sectur (2000). El turismo mexicano en el largo plazo. Memoria del Encuentro Nacional de Turismo: La perspectiva 2020. México: Secretaría de Turismo/Centro de Estudios Superiores de Turismo.

Sicilia, R. de (2000). "El corredor turístico Loreto-Nopoló-Puerto Escondido, Baja California Sur, en el contexto de los Centros Integralmente Planeados". Cuadernos de Turismo, 5, enero-junio, 53-68.

Tatoglu, E. et al. (2002). "Resident Attitudes Toward Tourism Impacts: The Case of Kusadasi in Turkey". International Journal of Hospitality \& Tourism Administration, 3 (3), 79-100.

Yutyunyong, T. y N. Scott (2009). "The Integration of Social Exchange Theory and Social Representations Theory: A New Perspective on Residents' Perception Research”. Ponencia presentada en la 18th Tourism and Hospitality Education and Research Conference. Queensland: University of Queensland. 